\title{
FATORES PREDITORES DA SÍNDROME DE BURNOUT EM ESTUDANTES DE UM CURSO TÉCNICO DE ENFERMAGEM
}

\section{ISABELLA CRISTINA MORAES CAMPOS}

Instituto Federal Sudeste de Minas Gerais - Campus São João del-Rei

E-mail: isabella.campos@ifsudestemg.edu.br

\section{MARcos SANTOS DE OLIVEIRA}

Universidade Federal de São João del-Rei

E-mail: mso@ufsj.edu.br

\section{ISABEL CRISTINA ADÃO}

Instituto Federal Sudeste de Minas Gerais - Campus São João del-Rei E-mail: isabel.schiavon@ifsudestemg.edu.br

\section{ERNANI COIMBRA DE OLIVEIRA}

Instituto Federal Sudeste de Minas Gerais - Campus São João del-Rei E-mail: ernani.coimbra@ifsudestemg.edu.br

\section{TATIANE APARECIDA DIVINO SILVA}

Instituto Federal Sudeste de Minas Gerais - Campus São João del-Rei E-mail: tatitads@hotmail.com

\section{StePHANIE ROdRIGUES CORTES GONÇALVES VIEIRA}

Instituto Federal Sudeste de Minas Gerais - Campus São João del-Rei E-mail: stephanieifsjdr@gmail.com

\section{RESUMO:}

Esta pesquisa investigou a síndrome de burnout e seus fatores preditores em 64 estudantes de um curso técnico em enfermagem de uma instituição federal de ensino de Minas Gerais, entre 18 e 50 anos $(M=25,56$ anos; $D P=0,38)$ que responderam ao Inventário de Burnout de Maslach - Student Survey e a um questionário sociodemográfico e escolar. A prevalência da síndrome foi 9,4\% e um grande número de estudantes apresentou risco de adoecimento (entre 37,5\% e 42,2\% da amostra, dependendo da subescala). Foram identificados os fatores sociodemográficos e escolares preditores da síndrome. Este estudo contribui para a discussão sobre o desenvolvimento da síndrome de burnout em estudantes de enfermagem, aumentando o conhecimento na área e permitindo a adoção de medidas preventivas e programas de intervenção nas instituições de ensino.

\section{PALAVRAS-CHAVE:}

Esgotamento profissional; enfermagem; educação técnica em enfermagem. 


\section{ABSTRACT:}

This study investigated Burnout Syndrome and its predictive factors in 64 students of a nursing technical course of a federal institution of education in Minas Gerais between 18 and 50 years ( $M=$ 25.56 years; Answered the Maslach Burnout Inventory - Student Survey and a sociodemographic and school questionnaire. The prevalence of Burnout syndrome was 9.4\%, and many students presented a risk of becoming ill (37.5\% to $42.2 \%$, for sample, depending on the subscale). The sociodemographic and scholastic factors predicting the syndrome were identified. This study contributes to the discussion about the development of burnout syndrome in Nursing students, increasing knowledge in the area, and adopting preventive measures and intervention programs in educational institutions.

\section{KEYWORDS:}

Burnout, professional; nursing. Education; nursing, associate.

\section{INTRODUÇÃO}

A síndrome de burnout, também chamada de síndrome do esgotamento profissional ou de sensação de estar acabado, é resultante da vivência profissional em um contexto com muitos estressores emocionais e relações sociais complexas (CAMPOS et al., 2015). Diversos autores atestaram que a exposição dos trabalhadores ao estresse laboral crônico seria uma condição indispensável para o desenvolvimento desse transtorno psiquiátrico que afeta profissionais que trabalham diretamente com outras pessoas, como os profissionais de saúde, que têm sido os mais estudados nos últimos anos, mas não exclusivamente (BENEVIDES-PEREIRA, 2002; CAMPOS et al., 2015;BAMBULA; GOMEZ, 2016;JOFRÉ; VALENZUELA, 2005; SILVA; CARLOTTO, 2008).

Ao ser submetido ao estresse no trabalho, a princípio, o trabalhador adota estratégias de enfrentamento (coping) como resposta aos agentes estressores. No entanto, se persistirem, esses agentes produzem mudanças negativas nas atitudes e no comportamento do profissional em relação aos clientes que atende (CAMPOS et al., 2015; ESCARÓN; BALADO, 2016; FUENTE et al., 2015; FAÚNDEZ, 2017).

Na síndrome, há inter-relação de suas três dimensões. A primeira, esgotamento emocional, é o seu elemento-chave e refere-se ao fato de que os indivíduos 
apresentam sentimentos de estarem emocionalmente esgotados e sobrecarregados, com falta de energia e entusiasmo. A despersonalização implica atitudes negativas, cínicas e impessoais, com sentimentos de distanciamento em relação às outras pessoas. A baixa realização pessoal no trabalho relaciona-se a sentimentos de incompetência e insucesso no trabalho e à tendência a se autoavaliar de forma negativa (MASLACH; JACKSON, 1981).

Há mais de 100 sintomas associados à doença (FAÚNDEZ, 2017). O trabalhador pode apresentar alterações afetivas e emocionais, tais como exaustão emocional, irritabilidade e ódio; atitudinais, como cinismo, despersonalização, apatia e agressividade; cognitivas, como desmotivação para o trabalho, dificuldade de concentração e baixa realização pessoal no trabalho; comportamentais, como isolamento, queixas constantes e absentismo; e fisiológicas, como insônia, cefaleia, fadiga e hipertensão (MASLACH; JACKSON, 1981).

Os profissionais mais susceptíveis ao adoecimento tendem a ser os mais motivados, que se entregam totalmente ao trabalho e investem muito mais energia do que recebem em termos de reconhecimento e resultados, mas, como reação ao estresse laboral, acabam por entrar em colapso (RITTER; STUMM; KIRCHER, 2009). Assim, na ausência de estratégias efetivas para a neutralização desses fatores estressores, a doença pode ocorrer, sendo caracterizada como uma síndrome de exaustão psíquica e exacerbação de sentimentos de esgotamento das emoções (MASLACH; JACKSON, 1981).

Os profissionais acometidos podem apresentar graves transtornos físicos e psicológicos que, muitas vezes, os incapacitam para o trabalho, podendo desenvolver, até mesmo, depressão (CARLOTTO; CÂMARA, 2008; SILVA; CARLOTTO, 2008), além do suicídio, que também foi citado como um possível desfecho no itinerário desses trabalhadores (TRIGO; TENG; HALLAK, 2007). 
Dentre os seus custos organizacionais, estão o absenteísmo, os pedidos de licença-médica e a alta rotatividade de pessoal. Há uma redução da qualidade do cuidado prestado, impactando negativamente na atenção oferecida aos pacientes. A qualidade do trabalho também fica comprometida pela desatenção e negligência do profissional, além de sua relação com a pessoa atendida se tornar mais distante, hostil e com menos empatia (BENEVIDES-PEREIRA, 2002; CARLOTTO; CÂMARA, 2008; GALINDO et al., 2012).

No entanto, o início da síndrome pode ocorrer ainda durante a fase acadêmica (CUSHWAY, 1992), pois estudar é uma ocupação estressante e os alunos podem apresentar diversas dificuldades. Muitas vezes, ainda estão em desenvolvimento fisiológico e social, mas já se encontram longe de suas famílias e se deparando com as expectativas de um futuro profissional incerto (ERTURGUT; SOYEKERCIB, 2010). A síndrome, nos estudantes, também pode estar relacionada ao sentimento de exaustão em razão das demandas dos estudos e da falta de relação teórico-prática, ocorrendo uma atitude de descrença e um sentimento de ineficácia profissional, isto é, de que o ensino não oportuniza aprendizagem útil para a formação profissional (SCHAUFELI et al., 2002).

O conceito de burnout em estudantes, assim como nos profissionais, também se constitui de três dimensões, a saber: exaustão emocional, caracterizada pelo sentimento de estar exausto em virtude das exigências do estudo; descrença, entendida como o desenvolvimento de uma atitude cínica e distanciada com relação ao estudo; e ineficácia profissional, caracterizada pelo sentimento de estarem sendo incompetentes como estudantes (SCHAUFELI et al., 2002).

Cabe ressaltar que, nos cursos da área da saúde, estão presentes diversos agentes estressores, tendo em vista que os estudantes são submetidos a situações similares às do trabalho, como, por exemplo, durante o estágio curricular. Os estudantes apresentam muitos medos, dentre eles, o medo de prejudicar o cliente, e 
o contato com os colegas e supervisores torna-se ameaçador. Os primeiros atendimentos prestados podem gerar ansiedade, incertezas, expectativas e receios. Há o temor de "fazer alguma coisa errada", o sentimento de desamparo em relação ao poder dos professores, atendimento a clientes difíceis, hostis em fase terminal, dilemas éticos, medo de contrair infecções durante os procedimentos, falta de tempo para lazer, família, amigos e necessidades pessoais, dentre outros (NOGUEIRAMARTINS, 2002).

Assim, observa-se que os alunos de um curso técnico de enfermagem estão vulneráveis ao desenvolvimento da síndrome de burnout. Por conseguinte, poderão ocorrer repercussões no seu futuro profissional, tanto para o contexto e as relações de trabalho, quanto para os diferentes sujeitos com quem interagem e para a qualidade do cuidado prestado (TOMASCHEWSKI-BARLEM et al., 2013).

Diante da importância da temática, foi realizada uma busca sistemática na literatura, por meio das bases de dados indexadas IBECS, LILACS, SciELO e Science Direct utilizando-se a combinação dos Descritores em Ciências da Saúde (DeCS) "enfermagem", "estudantes", "educação técnica em enfermagem" e "burnout"; "nursing", "students" "education, nursing, associate" e "burnout". Obtiveram-se apenas duas publicações (BORGES; CARLOTTO, 2004; CARLOTTO; CÂMARA; BORGES, 2005) específicas sobre a síndrome de burnout em estudantes de um curso técnico em enfermagem, o que reforça a relevância da pesquisa em tela.

Tal realidade revela que há uma escassez de estudos a respeito da síndrome de burnout com amostras específicas de alunos de cursos técnicos em enfermagem, bem como o estudo de suas variáveis preditoras, de forma que se conheça melhor o desenvolvimento da doença nesses discentes. Este estudo objetivou investigar a prevalência da síndrome de burnout nesses estudantes, além de identificar os seus fatores sociodemográficos e escolares preditores. 


\section{METODOLOGIA}

Esta pesquisa de levantamento, caracterizada como correlacional, transversal e de abordagem quantitativa, foi realizada em uma instituição de ensino federal de um município de médio porte do interior de Minas Gerais. Nessa instituição, o curso técnico em enfermagem é ofertado desde 2010 e desenvolve-se em quatro períodos, com carga horária teórica de 1.200 horas, somadas às 600 horas de estágio curricular obrigatório. As aulas teóricas são noturnas e o estágio, realizado nos dois últimos períodos do curso, ocorre no turno diurno.

A população-alvo deste estudo foi definida pelos seguintes critérios de inclusão: idade igual ou superior a 18 anos, ambos os sexos e frequentar o curso há, pelo menos, três meses. Foram excluídas as bolsistas do projeto de pesquisa, os alunos que estiveram de férias escolares nos três meses anteriores à coleta de dados, os afastados das atividades escolares, no momento da coleta, e aqueles que estiveram afastados por período igual ou superior a um mês e retornaram ao curso há menos de três meses. Não foi empregada técnica de amostragem da população-alvo. Dessa forma, todos os alunos que satisfizeram os critérios de inclusão e exclusão adotados fizeram parte da amostra desta pesquisa, considerando-se que não se tratava de um número excessivo de pessoas.

A coleta de dados ocorreu entre outubro e dezembro de 2014. Foram utilizados o Inventário de Burnout de Maslach-versão Student Survey (MBI-SS), cuja aplicação visou avaliar a ocorrência da síndrome de burnout entre os alunos, e um questionário sociodemográfico e escolar, que serviu para caracterização do perfil da amostra e levantamento dos possíveis fatores associados à síndrome.

O MBI-SS é a versão do instrumento específica para estudantes (SCHAUFELI et al., 2002), traduzida e adaptada para o Brasil (CARLOTTO; NAKAMURA; CÂMARA, 2006). Trata-se de uma escala de medida autoaplicada que apresenta frases 
afirmativas acerca dos sentimentos e atitudes dos alunos em relação aos seus estudos, avaliando as três dimensões da síndrome de burnout: exaustão emocional, descrença e eficácia profissional (SCHAUFELI et al., 2002).

O instrumento possui 15 itens, dos quais cinco se referem à dimensão exaustão emocional (itens 1, 4, 6, 8 e 12), quatro à descrença $(2,9,10$ e 14) e seis itens são relativos à eficácia profissional $(3,5,7,11,13$ e 15). Esta última subescala é avaliada de forma inversa, verificando, na verdade, o sentimento de ineficácia profissional nos alunos (CARLOTTO; CÂMARA, 2006).

As alternativas de resposta foram distribuídas em uma escala do tipo Likert de 5 pontos, de acordo com a frequência percebida pelo estudante do sentimento ou atitude que está sendo avaliada, sendo 1 = "nunca", 2 = "algumas vezes ao ano", 3 = "algumas vezes ao mês", 4 = "algumas vezes na semana", e 5 = "diariamente". Essa forma de pontuação foi considerada de mais fácil compreensão por parte dos respondentes (CAMPOS et al., 2015; CARLOTTO; CÂMARA, 2006; SILVA; CARLOTTO, 2008). As pontuações de cada item das subescalas são somadas. A versão do instrumento possui qualidades psicométricas adequadas, tanto de fidedignidade quanto de validade (CARLOTTO; CÂMARA, 2006).

O questionário foi elaborado para esta pesquisa e submetido a um estudo piloto. As variáveis que compuseram o instrumento foram selecionadas com base na literatura da área (BORGES; CARLOTTO, 2004; CAMPOS et al., 2015; CAMPOS; MAROCO, 2012; OLIVEIRA; CAREGNATO; CÂMARA, 2012;TOMASCHEWSKI-BARLEM et al., 2013). As variáveis sociodemográficas investigadas foram: sexo, idade, ter companheiro(a), município de residência, morar com os pais e/ou parentes, renda familiar mensal, renda per capita mensal, receber assistência estudantil da instituição de ensino, financiamento dos custos com os estudos, ter filho(s), número de filho(s), idade do(s) filho(s) e morar com o(s) filho(s). Os itens que foram empregados no levantamento das variáveis escolares estão elencados na seção "Resultados". 
A análise dos dados foi realizada por meio do software Statistical Package for the Social Sciences for Windows (SPSS), versão 20.0. Os testes estatísticos adotaram o nível de significância de $p<0,05$. Foi utilizada a estatística descritiva para caracterização da amostra e descrição das pontuações do MBI-SS por subescala. Para avaliar a prevalência da síndrome, as pontuações de cada dimensão foram somadas e categorizadas como: (a) baixa, com percentis $\leq 25$; (b) média, com percentis entre 25 e 75 e (c) alta, com percentis $\geq 75$ (CAMPOS et al., 2015; MENEGHINI; PAZ; LAUTERT, 2011). Pontuações elevadas em exaustão emocional e descrença e baixa em eficácia profissional foram indicativos da síndrome (SCHAUFELI et al., 2002).

Foram incluídas, nas análises de regressão logística subsequentes, as variáveis que apresentaram diferenças que se mostraram significativas $(p<0,05)$ e as variáveis que apresentaram valores de $p \leq 0,25$, pois poderiam se mostrar significativas nas análises de regressão (HOSMER; LEMESHOW, 2000). Foi empregada a técnica stepwise, considerando-se a probabilidade de entrada igual a 0,05 e, de saída, 0,10. A variável dependente foi a ocorrência da síndrome, em cada dimensão da doença, e as independentes foram as variáveis sociodemográficas e escolares. Para verificação da qualidade do ajuste do modelo de regressão logística, foi calculada a estatística de Hosmer-Lemeshow (HOSMER; LEMESHOW, 2000).

Foram seguidas as normas da Resolução no. 466 de 2012 do Conselho Nacional de Saúde. O desenvolvimento desta pesquisa obteve aprovação da Comissão de Ética em Pesquisa Envolvendo Seres Humanos do Instituto Federal Sudeste de Minas Gerais (Parecer no. 822.843). A coleta de dados apenas foi iniciada após essa aprovação, bem como a leitura e assinatura do Termo de Consentimento Livre e Esclarecido pelos estudantes. 


\section{RESULTADOS}

Foi obtida uma amostra de 64 estudantes, composta por 36 alunos (56,3\%) do segundo período e 28 alunos $(43,7 \%)$ do quarto período do curso técnico em enfermagem, sendo que 53 eram mulheres (82,8\%). A média de idade dos participantes foi 25,56 anos $(D P=0,38)$, variando entre 18 e 50 anos. A maioria dos alunos não tinha companheiro(a) (76,6\%), residia no município onde o curso é ofertado (57,8\%), moravam com pais e/ou parentes (70,3\%) e não tinha filhos $(68,8 \%)$.

A média da renda mensal per capita foi de 0,76 salários mínimos $(D P=0,50)$ e $86,4 \%$ dos estudantes possuíam renda per capita mensal igual ou inferior a um salário mínimo. Dentre os participantes, 30 alunos (47\%) recebiam algum tipo de assistência estudantil disponibilizada pela instituição de ensino, sendo que $61 \%$ eram os responsáveis por arcar com os custos dos estudos. Quase a metade da amostra $(48,4 \%)$ trabalhava. No grupo dos que já trabalhavam ou que estavam trabalhando no momento da coleta, 13 estudantes (20,3\%) já tinham experiência profissional na área de saúde e a profissão de Agente Comunitário de Saúde $(n=6)$ foi a mais citada. As variáveis escolares pesquisadas estão apresentadas na Tabela 1.

Tabela 1: Características escolares dos alunos - São João del-Rei, MG, Brasil, 2014.

\begin{tabular}{|c|c|c|}
\hline ITENS & SIM (n/\%) & NÃO (n/\%) \\
\hline Você concluiu o ensino médio em escola pública? & $62(96,9 \%)$ & $2(3,1 \%)$ \\
\hline Você está fazendo estágio curricular? & $25(39,1 \%)$ & $39(60,9 \%)$ \\
\hline Você realiza atividades extracurriculares? & $19(29,7 \%)$ & $45(70,3 \%)$ \\
\hline Você já se afastou do curso por licença-médica? & $6(9,4 \%)$ & $58(90,6 \%)$ \\
\hline Este curso técnico foi a sua primeira opção de curso? & $49(76,6 \%)$ & $15(23,4 \%)$ \\
\hline Você tem problemas de relacionamento com seus colegas de turma? & $16(25,0 \%)$ & $48(75,0 \%)$ \\
\hline Você tem problemas de relacionamento com seus professores? & $5(7,8 \%)$ & $59(92,2 \%)$ \\
\hline Você recebe apoio de seus colegas para realizar suas atividades escolares?* & $58(92,1 \%)$ & $5,9 \%)$ \\
\hline Você recebe apoio de seus professores para realizar atividades escolares?* & $59(93,7 \%)$ & $4(6,3 \%)$ \\
\hline Você está satisfeito(a) com o curso? & $56(87,5 \%)$ & $8(12,5 \%)$ \\
\hline Você acha que estuda em excesso? & $3(4,7 \%)$ & $61(95,3 \%)$ \\
\hline Você acha que os seus estudos podem Ihe causar desgaste físico e mental? & $19(29,7 \%)$ & $45(70,3 \%)$ \\
\hline
\end{tabular}




$\left.\begin{array}{|c|c|c|}\hline \text { Você considera que o seu curso é estressante? } & 25(39,1 \%) & 39(60,9 \%) \\ \hline \text { Você tem pensado em desistir do curso? } & 11(17,2 \%) & 53(82,8 \%) \\ \hline \text { Se tivesse uma oportunidade, faria outro curso técnico?* } & 33(52,4 \%) & 30(47,6 \%) \\ \hline \text { Você tem dificuldades de conciliar estudo e família? } & 25(39,1 \%) & 39(60,9 \%) \\ \hline \text { Você tem dificuldades de conciliar estudo e trabalho?** } & 24(60,0 \%) & 39(40,0 \%) \\ \hline \text { Você tem dificuldades de conciliar estudo e lazer? } & 25(39,1 \%) & 9(14,5 \%) \\ \hline \text { Você acha que estará apto(a) para trabalhar como técnico(a) de } \\ \text { enfermagem?* }\end{array}\right)$

*Itens não respondidos por todos os alunos. ** Respostas relativas apenas àqueles que trabalhavam.

Segundo o critério adotado por Schaufeli et at. (2002), seis alunos (9,4\%) satisfizeram os critérios de rastreamento da síndrome de burnout. O detalhamento das pontuações, por subescala do MBI-SS, está apresentado na Tabela 2.

Tabela 2: Distribuição das médias, desvios-padrão e nível de classificação das pontuações por subescala do MBI-SS - São João del-Rei, MG, Brasil, 2014.

\begin{tabular}{|c|c|c|c|}
\hline SUBESCALAS & MÉDIA $(D P)$ & NÍVEIS DE CLASSIFICAÇÃO & $\mathrm{n} / \%$ \\
\hline \multirow{3}{*}{ Exaustão Emocional } & \multirow{2}{*}{$14,17(3,58)$} & Baixa & $24(37,5 \%)$ \\
& & Média & $24(37,5 \%)$ \\
& & Alta & $16(25,0 \%)$ \\
\hline \multirow{2}{*}{ Descrença } & \multirow{2}{*}{$7,35(2,77)$} & Baixa & $19(29,7 \%)$ \\
& & Média & $27(42,2 \%)$ \\
& & Alta & $18(28,1 \%)$ \\
\hline \multirow{2}{*}{ Ineficácia Profissional } & $25,82(3,41)$ & Baixa & $18(28,1 \%)$ \\
& & Média & $25(39,1 \%)$ \\
& & Alta & $21(32,8 \%)$ \\
\hline
\end{tabular}

Foram feitas comparações dos grupos caso e não caso da síndrome de burnout, em relação aos fatores sociodemográficos e escolares. As variáveis categóricas foram submetidas ao Teste Qui-quadrado e a única variável contínua, idade, foi submetida ao Teste T para amostras independentes. Na Tabela 3, estão citadas as variáveis que apresentaram valores de $p \leq 0,25$. 
Tabela 3: Análises das variáveis sociodemográficas e escolares em função da designação dos participantes aos grupos caso e não caso de burnout - São João del-Rei, MG, Brasil, 2014.

\begin{tabular}{|c|c|c|c|}
\hline SUBESCALAS & VARIÁVEIS & ESTATÍSTICA & $p$ \\
\hline \multirow{12}{*}{$\begin{array}{l}\text { Exaustão } \\
\text { Emocional }\end{array}$} & Estado civil & $\chi^{2}(1)=1,422$ & 0,233 \\
\hline & Mora com pais e/ou parentes & $\chi^{2}(1)=3,019$ & 0,082 \\
\hline & Média semanal de horas de estudos & $\chi^{2}(1)=1,732$ & 0,188 \\
\hline & Problemas de relacionamento com colegas & $\chi^{2}(1)=4,000$ & $0,046^{*}$ \\
\hline & Satisfação com o curso & $\chi^{2}(1)=3,048$ & 0,081 \\
\hline & $\begin{array}{l}\text { Crença de que os estudos podem causar desgaste físico e } \\
\text { mental }\end{array}$ & $\chi^{2}(1)=11,004$ & $0,001^{* *}$ \\
\hline & Percepção de que o curso é estressante & $\chi^{2}(1)=4,923$ & $0,027^{*}$ \\
\hline & Intenção de desistir do curso & $\chi^{2}(1)=2,964$ & 0,085 \\
\hline & Dificuldades de conciliar estudo e família & $\chi^{2}(1)=7,899$ & $0,005^{* *}$ \\
\hline & Dificuldades de conciliar estudo e lazer & $\chi^{2}(1)=4,923$ & $0,027^{*}$ \\
\hline & Percepção de que estará apto(a) a trabalhar como TE & $\chi^{2}(1)=1,910$ & 0,167 \\
\hline & Crença de que conseguirá um emprego como TE facilmente & $\chi^{2}(1)=2,421$ & 0,120 \\
\hline \multirow{10}{*}{ Descrença } & Ter filho & $\chi^{2}(1)=2,029$ & 0,154 \\
\hline & Problemas de relacionamento com colegas & $\chi^{2}(1)=2,576$ & 0,108 \\
\hline & $\begin{array}{l}\text { Percepção de apoio dos colegas para realizar as atividades } \\
\text { escolares }\end{array}$ & $\chi^{2}(1)=2,629$ & 0,105 \\
\hline & Satisfação com o curso & $\chi^{2}(1)=9,938$ & $0,002 * *$ \\
\hline & $\begin{array}{l}\text { Crença de que os estudos podem causar desgaste físico e } \\
\text { mental }\end{array}$ & $\chi^{2}(1)=2,613$ & 0,106 \\
\hline & Intenção de desistir do curso & $\chi^{2}(1)=4,587$ & $0,032 *$ \\
\hline & Dificuldades de conciliar estudo e família & $\chi^{2}(1)=8,017$ & $0,005^{* *}$ \\
\hline & Dificuldades de conciliar estudo e lazer & $\chi^{2}(1)=5,115$ & $0,024^{*}$ \\
\hline & Percepção de que estará apto(a) a trabalhar como TE & $\chi^{2}(1)=8,149$ & $0,004^{* *}$ \\
\hline & Crença de que conseguirá um emprego como TE facilmente & $\chi^{2}(1)=17,920$ & $0,000 * *$ \\
\hline \multirow{10}{*}{$\begin{array}{l}\text { Ineficácia } \\
\text { Profissional }\end{array}$} & Idade & $t_{(62)}=-1,207$ & 0,232 \\
\hline & Estado civil & $\chi^{2}(1)=1,505$ & 0,220 \\
\hline & Município de residência & $\chi^{2}(1)=3,166$ & 0,075 \\
\hline & Ter filho & $\chi^{2}(1)=5,592$ & $0,018^{*}$ \\
\hline & Período do curso & $\chi^{2}(1)=1,678$ & 0,195 \\
\hline & Faz estágio curricular & $\chi^{2}(1)=2,341$ & 0,126 \\
\hline & Realiza atividades extracurriculares & $\chi^{2}(1)=2,036$ & 0,154 \\
\hline & Problemas de relacionamento com colegas & $\chi^{2}(1)=3,048$ & 0,081 \\
\hline & $\begin{array}{l}\text { Percepção de apoio dos professores para realizar as } \\
\text { atividades escolares }\end{array}$ & $\chi^{2}(1)=1,907$ & 0,167 \\
\hline & Satisfação com o curso & $\chi^{2}(1)=15,099$ & $0,000 * *$ \\
\hline
\end{tabular}




\begin{tabular}{|l|l|c|c|}
\hline \multirow{4}{*}{} & Intenção de desistir do curso & $\chi^{2}(1)=4,321$ & 0,038 \\
\cline { 2 - 4 } & Dificuldades de conciliar estudo e família & $\chi^{2}(1)=7,889$ & $0,005^{* *}$ \\
\cline { 2 - 4 } & Dificuldades de conciliar estudo e lazer & $\chi^{2}(1)=4,790$ & 0,029 \\
\cline { 2 - 4 } & Percepção de que estará apto(a) a trabalhar como TE & $\chi^{2}(1)=3,502$ & 0,061 \\
\cline { 2 - 4 } & Crença de que conseguirá um emprego como TE facilmente & $\chi^{2}(1)=7,200$ & $0,007^{* *}$ \\
\hline
\end{tabular}

${ }^{*} p<0,05 ;{ }^{*} p<0,01 ; \mathrm{TE}=$ técnico de enfermagem

A princípio, nas análises de regressão logística, apenas foram inseridas as variáveis escolares, visto que a literatura destaca a importância do contato do indivíduo com o mundo profissional no desenvolvimento da síndrome de burnout (CAMPOS et al., 2015; BENEVIDES-PEREIRA, 2002; KITZE; RODRIGUES, 2008). No segundo momento, também foram inseridas as variáveis sociodemográficas. A Tabela 4 apresenta os resultados referentes ao modelo final com as variáveis significativas ( $p$ $<0,05)$ preditoras da ocorrência da síndrome de burnout nos estudantes.

Tabela 4: Coeficientes estimados para o modelo de regressão logística, obtidos a partir das variáveis significativas, por dimensão. São João del-Rei, MG, Brasil, 2014.

\begin{tabular}{|c|c|c|c|c|c|c|}
\hline DIMENSÕES & VARIÁVEIS PREDITORAS & BETA & EP & WALD & $p$ & OR \\
\hline \multirow{4}{*}{$\begin{array}{l}\text { Exaustão } \\
\text { Emocional }\end{array}$} & Constante & $-4,095$ & 1,148 & 12,710 & $0,000 * *$ & 0,017 \\
\hline & Mora com pais e/ou parentes & 1,702 & 0,961 & 3,137 & 0,077 & 5,487 \\
\hline & $\begin{array}{l}\text { Crença de que os estudos podem } \\
\text { causar desgaste físico e mental }\end{array}$ & 1,913 & 0,710 & 7,253 & $0,007 * *$ & 6,773 \\
\hline & $\begin{array}{l}\text { Dificuldades de conciliar estudo e } \\
\text { família }\end{array}$ & 1,852 & 0,731 & 6,424 & $0,011^{*}$ & 6,371 \\
\hline \multirow{4}{*}{ Descrença } & Constante & $-3,760$ & 1,040 & 13,080 & $0,000 * *$ & 0,023 \\
\hline & Satisfação com o curso & 3,330 & 1,357 & 6,018 & $0,014 *$ & 27,943 \\
\hline & Intenção de desistir do curso & 3,312 & 1,213 & 7,454 & $0,006 * *$ & 27,434 \\
\hline & $\begin{array}{l}\text { Crença de que conseguirá um } \\
\text { emprego como TE facilmente }\end{array}$ & 3,825 & 1,135 & 11,351 & $0,001 * *$ & 45,827 \\
\hline \multirow{4}{*}{$\begin{array}{c}\text { Eficácia } \\
\text { profissional }\end{array}$} & Constante & $-3,288$ & 0,781 & 17,732 & $0,000 * *$ & 0,037 \\
\hline & Filho & 1,897 & 0,818 & 5,382 & $0,020 *$ & 6,668 \\
\hline & Satisfação com o curso & 3,055 & 1,040 & 8,637 & $0,003 * *$ & 21,231 \\
\hline & $\begin{array}{l}\text { Crença de que conseguirá um } \\
\text { emprego como TE facilmente }\end{array}$ & 1,762 & 0,796 & 4,900 & $0,027^{*}$ & 5,825 \\
\hline
\end{tabular}

$\mathrm{EP}=$ erro padrão; $p=$ nível descritivo; $\mathrm{OR}=$ Odds Ratio; ${ }^{*} p<0,05 ;{ }^{*} p<0,01 ; \mathrm{TE}=$ técnico de enfermagem 
Na dimensão exaustão emocional, o valor da estatística de Hosmer-Lemeshow foi 1,701, e o p-value, calculado a partir da distribuição Qui-Quadrado com 5 graus de liberdade, foi 0,889 , indicando que o referido modelo apresentou um bom ajuste. 0 valor de $R^{2}$ de Cox e Snell foi 0,269, apontando que 26,9\% das variações ocorridas na razão de chances foram explicadas pelo conjunto das variáveis que se mostraram significativas para a previsão da síndrome de burnout. Nas dimensões descrença e eficácia profissional, os valores de Hosmer-Lemeshow foram 4,275 ( $p=0,233)$ e 3,737 $(p=0,291)$, respectivamente, ambos com 3 graus de liberdade, e os $R^{2}$ de Cox e Snell foram $42,4 \%$ e 30,6 , respectivamente.

\section{DISCUSSÃO}

Observa-se que a prevalência da síndrome de burnout mostrou-se expressiva. Essa constatação é relevante, principalmente quando a esse dado é somado o grande número de alunos que obtiveram pontuações médias nas subescalas do MBI-SS e que, portanto, estão vulneráveis ao adoecimento. Por outro lado, nos outros dois estudos não tiveram alunos de cursos técnicos em enfermagem acometidos pela doença (BORGES; CARLOTTO, 2004; CARLOTTO; CÂMARA; BORGES, 2005).

No caso dos profissionais, mas que também pode se adotar, por similaridade, aos estudantes, os estressores ocupacionais, se persistentes, podem acarretar a síndrome de burnout (CAMPOS et al., 2015; SILVA; CARLOTTO, 2008). A detecção precocemente da síndrome possibilita a adoção de intervenções preventivas, impedindo o surgimento de possíveis dificuldades, tanto em nível escolar, pessoal e, futuramente, profissional. A prevenção da doença, desde a formação do estudante, é importante, pois, por prestar cuidado de saúde direto a outras pessoas, o profissional de enfermagem está constantemente sujeito a uma enorme variedade de fatores estressores e, consequentemente, ao desenvolvimento da síndrome de burnout (CAMPOS et al., 2015). 
A categoria profissional formada pelos técnicos de enfermagem é a mais numerosa e corresponde a 55,7\% dos profissionais de enfermagem (CONSELHO FEDERAL DE ENFERMAGEM, 2018). Tendo por base o grande número de estudantes que se formam anualmente, supõe-se que muitas pessoas podem vir a adoecer, ainda na vida acadêmica ou, posteriormente, já no mercado de trabalho.

Observa-se que as variáveis escolares foram as mais relevantes para o desenvolvimento da síndrome, com destaque para a insatisfação com o curso, que se mostrou como um fator de risco para a descrença e a baixa eficácia profissional, com razões de chances superiores a 27,0 e 21,0, respectivamente (a satisfação foi medida de forma inversa, 0 = satisfeito e 1 = insatisfeito, avaliando, desta forma, a insatisfação dos alunos com o curso).

Outra variável relevante foi "crença de que conseguirá um emprego como técnico de enfermagem facilmente", que aumentou em mais de 45 vezes a chance para a descrença, refletindo a incerteza dos alunos quanto à inserção no mercado de trabalho após a conclusão do curso. As pesquisas de Borges e Carlotto (2004) e Carlotto, Câmara e Borges (2005) também tiveram como variáveis mais relevantes as escolares. Similarmente, os pesquisadores da síndrome de burnout sempre destacaram os estressores ocupacionais contidos no ambiente laboral como as causas do surgimento da doença (CAMPOS et al., 2015; BENEVIDES-PEREIRA, 2002; KITZE; RODRIGUES, 2008).

No entanto, nesta pesquisa se pode observar que as variáveis sociodemográficas também surgiram como importantes preditoras da ocorrência da síndrome nos estudantes avaliados, mas em menor medida. É possível afirmar que morar com pais e/ou parentes pode aumentar as chances de os estudantes terem exaustão emocional em mais de cinco vezes e ter filho pode elevar o risco de ineficácia profissional em quase sete vezes. Talvez, isso possa ser explicado pelo fato de que, além das 
atribuições escolares, os estudantes que eram pais/mães tinham as responsabilidades de criarem o(s) filho(s).

Torna-se fundamental que a coordenação do curso e os docentes tomem uma postura de ouvintes das dificuldades e medos dos alunos como forma de reduzir a insatisfação com o curso, investigando as causas e tentando saná-las. O estágio curricular é um momento relevante, tendo em vista que os discentes são colocados frente ao novo e, muitas vezes, temem errar e colocar em risco as pessoas que atendem. Essa aproximação com a realidade do trabalho do técnico de enfermagem precisa ser gradual, iniciando-se por visitas técnicas, práticas em laboratório, até que os discentes se sintam preparados para iniciarem as atividades nos campos de estágio. Além disso, a organização do estágio deve preconizar que os professores sejam responsáveis por pequenos grupos de alunos, de forma que consigam, efetivamente, acompanhar cada um durante a realização dos procedimentos. Assim, os alunos se sentirão mais confiantes e seguros.

Outro aspecto importante é a oferta de ações de atendimento, de forma contextualizada, estreitando a relação estudante-instituição de ensino com vistas à melhoria da qualidade de vida do aluno. Muitos alunos são trabalhadores e têm filhos, portanto, precisam conciliar as atividades acadêmicas com as profissionais, domésticas e paternais. Nesse sentido, é importante que a instituição organize a oferta do curso, especialmente do estágio, de forma a favorecer a participação efetiva dessa parcela de alunos e que a aprendizagem seja potencializada.

Uma limitação do presente estudo consiste na impossibilidade de se generalizar os seus resultados para outras populações, suscitando novas pesquisas com amostras mais amplas e em diferentes contextos e regiões do país. Foram pesquisadas variáveis escolares pertinentes apenas à instituição de ensino avaliada, como a possibilidade de recebimento de verba de apoio estudantil. 
Um fator que impede a generalização dos resultados foi o emprego de percentis para avaliar os resultados do MBI-SS. Os valores de percentis de cada subescala foram calculados especificamente para a amostra deste estudo e essa técnica teve que ser adotada devido à falta de uma amostra normativa nacional na qual tenha sido adotada a escala Likert de 5 pontos. Além disso, outra dificuldade da escala percentílica reside no fato de ser uma escala ordinal, ou seja, não possui valor constante, representando apenas a posição relativa ou ordinal de cada indivíduo dentro do seu próprio grupo. Por esse motivo, não permite o cálculo da média, desvio-padrão e outras medidas estatísticas deles decorrentes (CAMPOS et al., 2015). Por outro lado, o fato da escala percentílica representar a posição relativa de cada sujeito dentro do seu próprio grupo confere uma maior validade interna aos dados de estudos que a empregam.

Finalmente, por esta pesquisa ser do tipo correlacional, não se pode garantir uma relação de causalidade entre os fatores associados. Desse modo, foram investigadas apenas as possíveis relações existentes entre essas variáveis pesquisadas e a doença.

\section{CONCLUSÃO}

Os dados verificados chamam a atenção para o risco do desenvolvimento da síndrome de burnout ainda durante a vida acadêmica e são preocupantes, tendo em vista que esses alunos ainda irão iniciar sua atuação como técnicos de enfermagem e, assim, ainda ficarão por anos sendo submetidos a diversos fatores estressores enquanto estiverem trabalhando. Os resultados obtidos com a realização dessa pesquisa também possibilitaram identificar quais variáveis estavam relacionadas à ocorrência da síndrome de burnout nesses estudantes, possibilitando, assim, uma reflexão sobre o processo de adoecimento dos estudantes de cursos técnicos em enfermagem e poderá lançar questões para pesquisas posteriores. 
Além disso, poderá subsidiar esforços para que se alcance uma forma de organização dos cursos que minimize seus possíveis efeitos nocivos à saúde dos alunos. Torna-se necessário um melhor preparo das instituições de ensino para a identificação precoce da síndrome de burnout, visando ao planejamento de estratégias preventivas e de seu tratamento, tendo em vista que pode acometer um número considerável de estudantes.

As pesquisas sobre a doença, tanto as internacionais quanto as nacionais, sempre focaram nas amostras compostas por trabalhadores e, portanto, os estudos com estudantes ainda são escassos. Tendo em vista que, já no curso técnico em enfermagem, ou até mesmo na graduação, os estudantes são submetidos a situações semelhantes às que ocorrem durante o trabalho em enfermagem, pesquisas semelhantes a essa são relevantes, de forma a se criar um conhecimento mais consistente sobre a temática.

Agradecimentos: Pesquisa com apoio financeiro da Direção de Pesquisa, Inovação e Pós-Graduação - Instituto Federal do Sudeste de Minas Gerais, Campus São João del-Rei.

\section{REFERÊNCIAS}

BENEVIDES-PEREIRA, A. M. T. (Org.).Burnout: quando o trabalho ameaça o bem-estar do trabalhador. São Paulo: Casa do Psicólogo, 2002.

BORGES, A. M. B.; CARLOTTO, M. S. Síndrome de burnout e fatores de estresse em estudantes de um curso técnico de enfermagem. Aletheia, n. 19, p. 45-56, 2004.

CAMPOS, I. C. M. et al. Fatores sociodemográficos e ocupacionais associados à síndrome de burnout em profissionais de enfermagem. Psicol. Reflex. Crit., v. 28, n. 4, p. 764-771, 2015. 
CAMPOS, J. A. D. B.; MAROCO, J. Adaptação transcultural Portugal-Brasil do Inventário de Burnout de Maslach para estudantes. Rev Saúde Pública, v. 46, n. 5, p. 816-824, 2012.

CARLOTTO, M. S.; CÂMARA, S. G. Análise da produção científica sobre a síndrome de burnout no Brasil. Psico, v. 39, n. 2, p. 152-158, 2008.

CARLOTTO, M. S.; CÂMARA, S. G. Características psicométricas do Maslach Burnout Inventory - Student Survey (MBI-SS) em estudantes universitários brasileiros. PsicoUSF, v. 11, n. 2, p. 167-173, 2006.

CARLOTtO, M. S.; CÂMARA, S. G.; BORGES, A. M. B. Predictores del síndrome de burnout en estudiantes de un curso técnico de enfermería. Diversitas: Perspectivas en Psicología, v. 1, n. 2, p. 195-204, 2005.

CARLOTtO, M. S.; NAKAMURA, A. P.; CÂMARA, S. G. Síndrome de burnout em estudantes universitários da área da saúde. Psico, v. 37, n. 1, p. 57-62, 2006.

CONSELHO FEDERAL DE ENFERMAGEM. Enfermagem em Números. [Internet]. Brasília; 2016. Disponível em:<http://www.cofen.gov.br/enfermagem-em-numeros>. Acesso em: 22 out. 2018.

CUSHWAY, D. Stress in clinical psychology trainees. British Journal of Clinical Psychology, v. 31, n. 2, p. 169-179, 1992.

BAMBULA, F. D.; GOMEZ, I. C. La investigación sobre el síndrome de burnout en latino america entre 2000 y el 2010. Psicol. Caribe, v. 33, n. 1, p. 113-131, 2016.

ERTURGUT, R.; SOYEKERCIB, S. An empirical analysis on burnout levels among second year vocational schools students. Procedia Social and Behavioral Sciences, v. 2, n. 2, p. 1399-1404, 2010. 
ESCARÓN, M. R.; BALADO, L. Grado de desgaste profesional em enfermeros de salas de quirófano de um hospital público, Montevideo, Uruguay. Revista Uruguaya de Enfermería, v. 11, n. 2, p. 60-77. 2016.

FUENTE, G. A. C. et al. Risk factors and prevalence of burnout syndrome in the nursing profession. International Journal of Nursing Studies, v. 52, n. 1, p. 240-249. 2015.

GALINDO, R. H. et al. Burnout syndrome among general hospital nurses in Recife. Rev Esc Enferm USP, v. 46, n. 2, p. 420-427, 2012.

HOSMER, D. W.; LEMESHOW, S. Applied logistic regression. (2nd ed). New York: John Wiley and Sons, 2000.

JOFRÉ, V. A.; VALENZUELA, S. S. Burnout em personel de enfermería de la unidad de cuidados intensivos pediátricos. Aquichan, v. 5, n. 1, p. 56-63, 2005.

KITZE, S.; RODRIGUES, A. B. Burnout em oncologia: um estudo com profissionais de enfermagem. Einstein, v. 6, n. 2, p. 128-133, 2008.

MASLACH, C.; JACKSON, S. E. The measurement of experienced burnout. Journal of Organizational Behavior, v. 2, p. 99-113, 1981.

MENEGHINI, F.; PAZ, A. A, LAUTERT, L. Fatores ocupacionais associados aos componentes da síndrome de burnout em trabalhadores de enfermagem. Texto Contexto Enferm., v. 20, n. 2, p. 225-233, 2011.

NOGUEIRA-MARTINS, M. C. F. Humanização das relações assistenciais: a formação do profissional de saúde. São Paulo: Casa do Psicólogo, 2002.

FAÚNDEZ, V. O. Laudatio: Dra. Christina Maslach, Comprendiendo El Burnout. Cienc Trab., v. 19, n. 58, p. 59-63, 2017.

OLIVEIRA, R.; CAREGNATO, R. C. A.; CÂMARA, S. G. Síndrome de burnout em acadêmicos do último ano da graduação em enfermagem. Acta Paul Enferm.,v. 25, n. spe. 2, p. 54-60, 2012. 
RITTER, R. S.; STUMM, E. M. F., KIRCHER, R. M. Análise de burnout em profissionais de uma unidade de emergência de um hospital geral. Rev. Eletr. Enf., v. 11, n. 2, p. 236248, 2009.

SCHAUFELI, W. B. et al. Burnout and engagement in university students: a crossnational study. J Cross Cult Psychol, v. 33, n. 5, p. 464-481, 2002.

SILVA, T. D.; CARLOTTO, M. S. Síndrome de burnout em trabalhadores da enfermagem de um hospital geral. Rev. SBPH, v. 11, n. 1, p. 113-130, 2008.

TOMASCHEWSKI-BARLEM, J. G. et al. Manifestações da síndrome de burnout entre estudantes de graduação em enfermagem. Texto Contexto Enferm., v. 22, n. 3, p. 754762, 2013.

TRIGO, T. R.; TENG, C. T.; HALLAK, J. E. C. Síndrome de burnout ou estafa profissional e os transtornos psiquiátricos. Rev. Psiq. Clín., v. 34, n. 5, p. 223-233, 2007. 